\title{
Assessment of the Grazemore dairy cow model to predict performance of grazing dairy cows fed forages
}

\author{
A.V. Chaves ${ }^{1}$, J.-L. Peyraud, R. Delagarde and P. Faverdin \\ Unité Mixte de Recherches Production du Lait, Institut National de la Recherche Agronomique \\ 35590, St-Gilles, France
}

\begin{abstract}
The goal of this work was to determine the accuracy of the Grazemore model to predict milk yield and dry matter intake (DMI) of grazing cows fed pasture and forage supplements. Data were obtained from studies where pasture was complemented with silages, comprising $30-40 \%$ of DMI. Twelve dietary mixtures were used in this evaluation. Liveweight, days in milk, pre-grazing mass, allowance and diet composition were collected during the trials and used as inputs. There was a good correlation between actual and predicted milk yield $\left(\mathrm{r}^{2}=0.72\right)$ and DMI $\left(\mathrm{r}^{2}=0.90\right)$ by the model when actual production was regressed against predicted responses.
\end{abstract}

KEY WORDS: dairy cows, modelling, pasture, silages

\section{INTRODUCTION}

A dairy cow herbage intake model (HIM) was recently produced (Delagarde et al., 2004) as part of the EU funded called "Grazemore". The Grazemore-HIM is a computer model that predicts intake and milk yield for a group of cows under rotational or continuous grazing, from a wide range of forage species, supplementary feeds (forages or concentrates) and grazing management practices. GrazemoreHIM is based on the INRA feeding value standards where many equations and feed values are derived. These feeding values were applied to grazing cows assuming that fill value of grass is modified by the grazing conditions. Cow-diet effects take in account the herbage allowance, pre-grazing sward mass and allowance on rotational grazing and daily access time to the pasture.

There are numerous statistical tools available for evaluating the accuracy and precision of models that predict animal performance. These tools include plots

\footnotetext{
${ }^{1}$ Corresponding author: e-mail: chaves@st-gilles.rennes.inra.fr
} 
of predicted and observed values, mean squares prediction error analysis, and analysis of residuals against predictions.

The aim of this study was to determine the robustness and utility of the GrazemoreHIM to predict dry matter intake (DMI) and milk yield of cows fed pasture and silage supplements, using data obtained from two dairy cow trials conducted in mid-lactation where pasture was complemented with contrasting silages.

\section{MATERIAL AND METHODS}

\section{Cow trials used for model evaluation}

The data against which the model predictions were tested were derived from twelve rations (treatments means) in two trials carried out in Hamilton (Chaves et al., 2002; Woodward et al., 2002). Each trial comprised 60 Friesian cows (10/treatment) averaging $528 \pm 17 \mathrm{~kg}$ of liveweight (LW); $17 \pm 2.4 \mathrm{~kg}$ milk/day; $156 \pm 15$ days in milk. Cows were grazed on ryegrass (Lolium perenne) and white clover (Trifolium repens) pasture (allowance $18-50 \mathrm{~kg} \mathrm{DM} / \mathrm{cow}$ per day) complemented by contrasting silage supplements contributing $30-40 \%$ of DMI. Each trial was 4 weeks in duration and silage supplements included maize (M; Zea mays), sulla (S; Hedysarum coronarium), pasture, Lotus corniculatus (LC) and mixtures of $\mathrm{M}$ and $\mathrm{S}$.

\section{Inputs}

Animal characteristics (age, days pregnant and since calving, number of lactation, LW, body condition score), management practices (pre-grazing mass, area per animal, forage and grazing type) and feed composition from the twelve rations were used as inputs in the Grazemore-HIM. The data were used to examine the model predictions for trial means (four weeks each trial) over all treatments.

\section{Model evaluation and statistical analysis}

Model evaluation should include a rigorous statistical component and in this study two different methods have been used to evaluate the Grazemore-HIM predictions. Most often, predictions are evaluated by regressing actual values versus predicted responses (Method 1: linear regression). An alternatively measure of how well model predictions fit observed data, can be calculated as the root mean square prediction error (RMSPE):

$$
\text { RMSPE }=\sqrt{ }\left[\sum(\text { predicted }- \text { actual })^{2} / \text { number of observations }\right]
$$

This term is the square root of the estimate of variance of actual values about the predicted values. The RMSPE is comprised of two terms which identify systematic problems with models: the mean bias and the residual error (Method 2: measures of deviation). The mean bias represents the average inaccuracy of model 
predictions across all data and the residual error is the remaining error in model prediction after accounting for the mean bias.

Mean bias $=\sum$ (predicted - actual $) /$ number of observations

Residual error $=\sum\left[\mathrm{RMSPE}^{2}-(\text { mean bias })^{2}\right]$

\section{RESULTS}

Mean predictions (Pr) of cow performance, based on model simulations from DMI and milk yield are compared with actual (A) values in Table 1. The model under-predicted mean DMI (12.0 vs actual $13.9 \mathrm{~kg}$ DMI/cow/day) and the mean of predicted milk production based on dietary composition were identical to actual values.

Table 1. Actual (A) and predicted (Pr) values, regressions, correlations, bias and errors for dry matter intake (DMI) and milk production (all kg/cow/day)

\begin{tabular}{|c|c|c|c|c|c|c|c|c|c|c|c|c|}
\hline \multirow[b]{2}{*}{ Item } & & \multicolumn{6}{|c|}{ Method 1 (linear regression) } & \multicolumn{5}{|c|}{ Method 2 (measures of deviation) } \\
\hline & & $\begin{array}{l}\text { mean } \\
\text { value }\end{array}$ & $\begin{array}{c}\text { inter- } \\
\text { cept }\end{array}$ & slope & $r^{2}$ & $\mathrm{MSE}^{\mathrm{a}}$ & $\mathrm{P}^{1}$ & $\begin{array}{l}\text { mean } \\
\text { bias }^{\text {b }}\end{array}$ & $\begin{array}{c}\text { residual } \\
\text { error }^{\mathrm{c}}\end{array}$ & $\mathrm{RMSPE}^{\mathrm{d}}$ & $r^{2}$ & $\mathrm{P}^{2}$ \\
\hline DMI & $\mathrm{A}$ & 13.9 & & & & & & & & & & \\
\hline & $\operatorname{Pr}$ & 12.0 & -6.65 & 1.73 & 0.90 & 0.73 & $<0.01$ & $-2.50^{\mathrm{ns}}$ & 1.1 & 2.8 & 0.62 & 0.06 \\
\hline Milk & $\mathrm{A}$ & 15.4 & & & & & & & & & & \\
\hline yield & $\operatorname{Pr}$ & 15.4 & 3.84 & 0.72 & 0.72 & 0.86 & $<0.01$ & $0.55^{\mathrm{ns}}$ & 0.93 & 1.08 & 0.29 & 0.07 \\
\hline
\end{tabular}

\section{Method 1 - Linear regression of actual against predicted values}

A linear regression between actual DMI and Grazemore-HIM predictions had a positive slope and a strong relationship between the model prediction and actual values $\left(\mathrm{P}<0.001 ; \mathrm{r}^{2}=0.90\right)$. This analysis shows small unexplained source of variation (residual variance or mean square error (MSE)) of $0.73 \mathrm{~kg} \mathrm{DMI} /$ day and the correlation shows the prediction for most of individual diets will be good.

Comparisons between actual and predicted values for milk production based on feed composition also demonstrated good model performance (Table 1).

\section{Method 2 - Deviation of prediction from actual values}

When model predictions were tested using measures of deviation, mean bias was not statistically significant from zero for DMI and milk production. The residual error terms represent the error in prediction after accounting for the mean bias. 
The slope of the regression line was not significantly greater than zero for milk production and for DMI. This indicates that there is not a systematic bias, where the residual differences did not increase at higher predicted values. However, Table 1 shows that the most important (highest $\mathrm{r}^{2}$ ) biases for the Grazemore was for DMI (slope $=-0.73)$.

\section{DISCUSSION}

The lack of a significant mean bias for any of the parameters examined suggests very good model prediction. In addition, the analyses carried out showed that accurate predictions of mean values demonstrate good predictability for individual diets (residual error is small; Table 1), and the utility of the GrazemoreHIM for fresh forages is promising.

The mean actual and predicted milk yields were similar $(15.4 \mathrm{~kg} /$ day $)$ and the regression explained $72 \%$ of the variance across the diets. When residuals were regressed against predicted milk production (Method 2), there was no significant mean bias, and residual differences did not change for values above and below mean predicted milk production.

\section{CONCLUSIONS}

The potential of the Grazemore-HIM to predict milk production and DMI from diets based on pasture and forage supplements were tested using information from dairy cow trials. The results indicate good predictions for milk production and DMI. This mechanistic model has potential benefits for dairy nutrition because it does accommodate feed supply, which has a major effect on performance of grazing animals.

\section{REFERENCES}

Chaves A.V., Woodward S.L., Waghorn G.C., Brookes I.M., Holmes C.W., Laboyrie P.J., 2002. Post-peak supplementation of pasture fed dairy cows with sulla and maize silages. Proc. N. Z. Grassl. Assn. 64, 125-128

Delagarde R., Faverdin P., Baratte C., Bailhache M. Peyraud J.L., 2004. The herbage intake model for grazing dairy cows in the EU grazemore project. Proceedings of the 20th General Meeting of the European Grassland Federation, Lucerne (Switzerland) (in press)

Woodward S.L., Chaves A.V., Waghorn G.C., Laboyrie P.J., 2002. Supplementing pasture-fed dairy cows with pasture silage, maize silage, Lotus silage or sulla silage in summer- does it increase production? Proc. N. Z.. Grassl. Assn. 64, 85-89 